\section{FGF-21 IN INFLAMMATORY BOWEL DISEASES}

P.J. Tomasik ${ }^{1}$, S.H. Pieczarkowski², K. Fyderek², K. Sztefko ${ }^{1}$

${ }^{1}$ Department of Clinical Biochemistry, ${ }^{2}$ Clinic of Pediatric, Gastroenterology and Nutrition, Jagiellonian University Medical College, Krakow,

\section{Poland}

Fibroblast growth factor 21 (FGF-21) is an atypical member of the FGF family. It act as an endocrine hormone which affects energy balance. In humans FGF-21 was correlated with obesity. The relationship ofFGF-21 and starvation in the course ofinflammatory bowel diseases (IBD) is unknown. Therefore the FGF-21 concentrations in children with IBD $(n=22)$ and obese children $(n=17)$ were investigated. Subjects were in similar age (14 \pm 3 ys.). The mean $\mathrm{BMI}$ of obese children were $30 \pm 6 \mathrm{~kg} / \mathrm{m} 2$ whereas in IBD group $16 \pm 2,2 \mathrm{~kg} / \mathrm{m} 2$. The FGF-21 in IBD children were measured triple - in acute stage of the disease, during the treatment and in the remission. FGF-21 concentrations were determined in fasting serum samples using RIA. The highest FGF-21 concentrations (mean $0,7 \pm 0,16 \mathrm{ng} / \mathrm{ml}$ ) were noted in acute stage of IBD. The results in samples taken during the treatment and in remission were similar $(0,53 \pm 0,17 \mathrm{ng} / \mathrm{ml}, 0,48 \pm 0,09 \mathrm{ng} / \mathrm{ml}$, respectively; $\mathrm{p}<0,05$ as compare to results determined in acute stage of disease). The mean concentration of FGF21 in obese subject was $0,58 \pm 0,12 \mathrm{ng} / \mathrm{ml}$; and this value also was significantly lower than observed in acute stage of IBD. The serum levels of FGF-21 in obese group and IBD children during remission correlate with BMI $(r=50 ; p<0,05)$. These results suggest that FGF-21 concentration reflect the imbalance in energy intake/expenditure, however the inflammation in IBD increase serum levels of this parameter. Therefore usefulness of FGF-21 as a marker of energy balance in acute stage of IBD and probably in other inflammatory disorders is limited.

\section{3}

\section{NUTRI-MEDICINAL PLANTS USAGE IN THE MANAGEMENT OF IMMUNO-COMPROMISED AILMENTS IN UGANDA}

\section{M.M. Kamatenesi}

Botany, Makerere University, Kampala, Uganda

Introduction: To regard food as medicine is part of cultural heritage. Today, more advanced scientific research reveals that human health is directly connected to nutrition (Johns, 2003, Lentini et al., 2007). FAO, (2003) observed that wild food plants have a potential in the mitigation of HIVIAIDS impact, especially among the rural poor. In Uganda, $80 \%$ of mothers use traditional medicine to provide health care for themselves and children (Kamatenesi et al, 2005, Kamatenesi and Oryem-Origa 2006).

Objective of the study: This study inventoried nutritional medicinal plants and performed the nutritional analysis of some nutri-medicinal plants used in most parts of Uganda.

Methods: The methods used for field surveys were semi-structured interviews, discussions, health centre surveys, focused group discussions. The Laboratory research was conducted in the Department of Food Science and Technology, faculty of Agriculture, Makerere University, Uganda, using standard methods and following the standard operating procedures used in the laboratory for nutrient and mineral analysis.

Research results: The research findings revealed that vegetables such as Amaranthus graecizans, Solanum nigrum, Cleome gynandra, are rich in nutrients and micronutrients.

Conclusion and Recommendation: Plants used as food plants by local communities are potent in immune boosting and restoring appetite loss to pregnant women, children and other immunocompromised patients. However, mores studies on biosafety are needed in validating indigenous knowledge in nutritional plants. Thus, this paper will present the value of food plants that double as medicinal plants in health care delivery in Uganda.

Key words: Nutri-medicinal plants; immune boosting; nutritional analysis; Uganda.

1054

\section{ASSOCIATION BETWEEN MARKERS OF BONE METABOLISM, IGF I AND LEPTIN IN MALNURISHED INFANTS}

W. Furmaga-Jablonska1', B. Kulik-Rechberger ${ }^{2}$, E. Wojcik-Skierucha ${ }^{1}$, G. Polkowska ${ }^{1}$

'Departament of Neonates' and Infants' Pathology, ${ }^{2}$ Departament of Paediatric Propedeutics, Medical University of Lublin, Lublin, Poland

The aim of our study was to detect the association between cytokines that are essential for bone 
health, e.g. osteoprotegerin (OPG), s-RANKL and markers of nutritional status, e.g. somatomedin I $(\lg \mathrm{F} I)$, leptin in malnourished infants.

The study comprised of 86 infants ( 42 boys and 44 girls) between the $4^{\text {th }}$ and $7^{\text {th }}$ months of age. According to their position of body weight and BMI at percentile charts for sex and age two groups were created: group I consisted of 54 malnurished infants with body weight and BMI $(11.9)<3^{\text {rd }}$ percentile, group II consisted of 32 infants with body weight and BMI (15.5) between the $10^{\text {th }}$ and $90^{\text {th }}$ percentile. Biochemical investigations: OPG (pmol/l), s-RANKL (pmol/l), lgF I (ng/ml) and leptin $(\mathrm{ng} / \mathrm{ml})$ were performed in all the infants The study protocol was approved by the Ethics Committee of Medical University of Lublin.

Statistical analysis was performed with t-Student and Spearman's correlation rank tests. $\mathrm{P}<0.05$ was regarded as significant.

Results: There were no statistical differences confirmed between the level of OPG and IgF I in the studied groups $(p>0.05)$. Statistical difference was confirmed for the level of leptin and s-RANKL between groups I and II $(p<0.001, p<0.05$ respectively).In malnourished infants (group I ) statistically significant correlation was detected between the level of s-RANKL and IGF I $(r=0.39$, $p<0.05)$

Conclusion: Results of our study confirmed that malnutrition may influence bone metabolism in infants.

\section{5}

\section{ALL-IN-ONE VERSUS TWO-COMPARTMENT PARENTERAL NUTRITION IN EXTREMELY PRETERM INFANTS < 27 WEEKS GESTATION AND $<1000$ G BIRTHWEIGHT (ELBWI)}

S.S.R. Doyle ${ }^{1}$, J.R. Fernandez-Alvarez ${ }^{2}$, M. Pettit ${ }^{3}$, H. Rabe ${ }^{2}$

${ }^{1}$ Brighton \& Sussex Medical School, ${ }^{2}$ Department of Neonatology, Brighton \& Sussex University Hospitals NHS Trust, ${ }^{3}$ Pharmacy Department / School of Pharmacy, Brighton \& Sussex University Hospitals NHS Trust / University of Brighton, Brighton, UK

Background and aims: Evidence suggests standardized total parenteral nutrition (TPN) confers benefits over individualized TPN in terms of availability, nutritional intake, cost-effectiveness and maybe patient safety (e.g. infections). However, it is unclear whether all-in-one or two-comparment (lipid separate) standardised preparations are more beneficial. This study aims to specifically address this question in a group of ELBWI.

Methods: A retrospective matched-pair cohort analysis was carried out of 25 ELBWI $\leq 27$ weeks gestation, born at the Royal Sussex County Hospital, Brighton (UK), between January 2005 - December 2006 and January - December 2008. The early cohort received all-in-one TPN, while the later received two-component. They were matched for gestation, birth weight, admission duration, age at initiation and duration of TPN, and additional enteral feeds. Small for gestational age infants and infants with congenital anomalies were excluded. Clinical outcomes were daily weight gain, infectious and metabolic complications, and oxygen requirement at discharge. Daily cost of treatment was also compared.

Results: There was no statistically significant difference in daily growth, triglyceride and bilirubin levels, oxygen requirement at discharge or financial cost.

There was a statistically significant increase in episodes (5 [range 3-9] vs. 3 [range 1-6]; $p=0.016$ ) and days of antibiotic treatment (33 [range 14-62] vs. 20 [range 5-51]; $p=0.017$ ) in the all-in-one group.

Conclusion: All-in-one TPN seems to increase the risk of infection without conferring any clinical or economic benefits. Its use in ELBWI should probably be abandoned.

\section{6}

CARDIOVASCULAR DISEASE SECONDARY TO VITAMIN D DEFICIENCY : CASE SERIES OF THREE CHILDREN

P.K. Arora, P. Kapila

Paediatrics, North Middlesex Hospital, London, UK

Deficiency of vitamin $D$ can result from a number of factors like inadequate dietary intake, coupled with inadequate sunlight exposure and disorders that limit its absorption. Although the most recognised complication of deficiency is musculoskeletal, there is growing awareness of its impact on the cardiovascular system. 